\title{
Cluster analysis of variations in the diurnal pattern of grass pollen concentrations in Northern Europe (Copenhagen) and Southern Europe (Córdoba)
}

\section{Diurnal pattern of grass pollen}

Purificación Alcázar ${ }^{\mathrm{a}}$, Pia Viuf Ørby ${ }^{\mathrm{b}}$, Jose Oteros ${ }^{\mathrm{c}^{*}}$, Carsten Skjøth ${ }^{\mathrm{d}}$, Ole Hertel ${ }^{\mathrm{e}}$, Carmen Galán ${ }^{\mathrm{a}}$

a. Department of Botany, Ecology and Plant Physiology. University of Córdoba, Córdoba, Spain.

b. Department of Public Health. Aarhus University. Aarhus, Denmark.

c. Center of Allergy \& Environment (ZAUM), Member of the German Center for Lung Research (DZL), Technische Universität München/Helmholtz Center, Munich, Germany.

d. National Pollen and Aerobiology Research Unit, Institute of Science and the Environment, University of Worcester, Worcester, United Kingdom.

e. Department of Environmental Science, Aarhus University, Denmark.

*Corresponding author: Jose Oteros

Biedersteiner str. 29 (ZAUM), 80802 Munich (Germany)

oterosjose@gmai.com; phone: +49 -89-41403486 
From an allergological point of view, Poaceae pollen is one of the most important type of pollen that the population is exposed to in the ambient environment. There are several studies on intradiurnal patterns in grass pollen concentrations, and agreement on the high variability. However, the method for analysing the different patterns is not yet well established. The aim of the present study is therefore to examine the method of pattern analysis by statistical clustering, as well as relating the proposed patterns to time of season and meteorological variables at two highly different biogeographical locations; Córdoba, Spain and Copenhagen, Denmark.

Airborne pollen is collected by Hirst type volumetric spore traps and counted using an optical microscope at both sites. The counts were converted to two-hours concentrations and a new method based on cluster analysis was applied with the aim of determining the most frequent diurnal patterns in pollen concentrations and their dependencies of site, season and meteorological variables.

Three different well defined diurnal patterns were identified at both locations. The most frequent pattern in Copenhagen was associated with days having peak pollen concentrations in the evening (maximum between18h-20h), whereas the most frequent pattern at Córdoba was associated with days having peak pollen concentrations in the afternoon (maximum between $14 \mathrm{~h}-16 \mathrm{~h}$ ). These three patterns account for $70 \%$ of days with no rain and pollen concentrations above 20 grains $\mathrm{m}^{-3}$. The most frequent pattern accounts for $40 \%$ and $57 \%$ of the days in Córdoba and Copenhagen respectively. The analysis clearly shows the great variation in pollen concentration pattern, albeit a dominating pattern can be found.

It was not possible to explain all the differences in the patterns by the meteorological variables when examined individual. Clustering method is estimated to be an appropriate methodology

Keywords: Poaceae pollen, bioaerosols, clustering, hourly, aerobiology, meteorology, air 
Grass pollen is one of the most important from an allergological point of view, being the most important casue of pollinosis in extensive areas of the World like Europe (D'Amato et al., 2007). It is the most widespread pollen (Skjøth et al., 2013a) and may be considered as the most important cause of pollinosis in Europe due to a long season (Smith et al., 2014), its wide-spread distribution (Skjøth et al., 2013b) and the generally very high number of sensitizations (Burbach, 2009; D'Amato et al., 2007). Numerous species contribute to the concentration of this pollen (Kraaijeveld et al., 2015). Different grass species flower at different times of the year (Beddows, 1931; Jones, 1952) and day, this may affect the diurnal patterns in pollen from this family. As an example, Agrostis and Festuca flower at midday whereas Anthoxanthum and Holcus flower in the morning or late afternoon (Hyde and Williams, 1945; Peel et al., 2014). A number of studies have demonstrated an afternoon maximum in the concentrations of grass pollen (e.g. Goldberg et al., 1988; Simoleit et al., 2015). Nevertheless, variations in airborne grass pollen concentrations are not solely related to time of anthesis. Due to their transport and dispersion in the air, pollen concentrations also depend on atmospheric conditions like urban atmospheric stability and local breezes (Puc, 2012; Pérez-Badia et al., 2011; Muñoz Rodríguez et al., 2010; Kasprzyk, 2006). Every day, it happens the upward moving of thermals with pollen grains to higher elevation and when convection currents cease at the end of the afternoon, suspended particles are subject to gravitational settling which lead to increasing pollen concentrations at lower height.

Airborne grass pollen in Copenhagen (Denmark) and Cordoba (Spain) are likely to have different diurnal patterns, and no previous studies have reported multiple diurnal patterns for either site. This difference is caused by considerable differences in climate and species composition as described by base maps used in the habitat directive (e.g. http://www.eea.europa.eu/data-and-maps/data/biogeographical-regionseurope). Also differences in local relief could affect the patterns, as Cordoba is highly affected by the surrounding mountains, and Copenhagen is located at a flat coastal position.

Grass pollen concentrations originate from an amalgam of species (García-Mozo et al., 2010). However, in Cordoba (Spain) it has been shown that just four Poaceae species are the dominating contributors to pollen concentrations (León-Ruiz et al., 2011; Cebrino et al., 2016) while other regions, such as Leiden in Northern Europe, have different profiles (Kraaijeveld et al., 2015). Meteorological effects 
of specific grass species responsible for the early season profile, as the one observed by Peel et al. (2014).

81 Long term studies and interregional comparisons are therefore important. Previous studies conducted in

82 Cordoba have showed that the diurnal pattern in grass pollen concentration was homogeneous

83 throughout the study years. These patterns showed an increase early in the morning, a moderate

84 decrease in the afternoon, and stable values throughout the night (Galán et al., 1989; Cariñanos et al.,

85 1999; Alcázar et al., 1999). A previous study in Copenhagen has shown the maximum frequency of pollen

86 peak concentrations during the afternoon (Goldberg et al., 1988), whereas a recent study showed

87 seasonal variation in the profile (Peel et al., 2014).

Determining the actual concentrations of pollen including the diurnal pattern is an important element in providing advice to patients on allergen avoidance during peak hours in pollen concentrations

90 (Sommer et al., 2009). These patterns can vary over the season and can be specific to the geographical

91 region. A single unified pattern therefore has limitations. The diurnal pattern and its potential variations

92 are of importance for patients suffering from allergy as well as for doctors that are studying allergic rhinitis

93 or treating and guiding patients. Until now primarily seasonal averaged diurnal pattern in pollen 94 concentrations have been available in literature and the interest in bringing this a step forward and 95 provide diurnal pattern as function of time of season and meteorological conditions is the background for 96 the presented work.

97 The aim of this paper was to analyse the variation in diurnal patterns of grass pollen concentrations in Copenhagen (Denmark) and Cordoba (Spain). The diurnal patterns in two-hours pollen concentrations are examined by a new method based on statistical clustering to objectively reveal groups solely based on pattern and relate these to meteorology and time of season. 
This study investigates the measured two-hours pollen concentrations (concentration of pollen during periods of two hours) from two pollen traps in the cities of Copenhagen and Cordoba (Fig.1). Continuous monitoring of pollen in the air is carried out from Hirst type volumetric spore traps (Hirst, 1952). Air is sucked into the trap at a rate of $10 \mathrm{~L} / \mathrm{min}$ through a $2 \mathrm{~mm} \times 14 \mathrm{~mm}$ orifice. Behind the orifice, the air flows over a rotating drum that moves past the inlet at $2 \mathrm{~mm} / \mathrm{h}$. The drum is covered with an adhesive coated, transparent plastic tape, which traps the particles through impaction.

>>Figure 1

Copenhagen is the capital of Denmark. It is situated on the eastern coast of Zealand island $\left(55^{\circ} 40^{\prime} \mathrm{N}, 12{ }^{\circ} 34^{\prime} \mathrm{E}\right), 20 \mathrm{~m}$ a.s.l. The city is in located on low lying flat ground near the coast and subject to low pressure systems from the Atlantic resulting in unstable conditions throughout the year. The area is mainly urban with agricultural surroundings and biogeographically located in the northern part of the

117 continental region with little distance to the Atlantic and Boreal regions. The annual diurnal mean 118 temperature is $8^{\circ} \mathrm{C}$ and the annual precipitation is $613 \mathrm{~mm}$ with rainfall fairly evenly distributed throughout the year. Weather data is obtained from near the pollen trap, including hourly measurements of temperature, wind speed and direction. Daily precipitation is from the nearby synoptic meteorological 121 site at Kastrup airport (USAF-ID 061800), obtained from the data set Global Summary of the Day 122 exchanged by World Meteorological Organisation. The pollen trap is situated $15 \mathrm{~m}$ above ground level on 123 the roof of the Danish Meteorological Institute $\left(55^{\circ} 43 \mathrm{~N}, 12^{\circ} 34 \mathrm{E}\right)$. The Copenhagen pollen monitoring 124 station is part of the permanent Danish pollen monitoring network, and is typically in continuous 125 operation from January to October.

The typical grass pollen season in Denmark is from end of May till end of August, peaking at the 127 end of June, with an average annual pollen integral of 2200 grains * day $/ \mathrm{m}^{3}$, varying from 588 to 3222 128 (1985-2009). Peak daily pollen concentration occurred in 2004 with 320 pollen grains $/ \mathrm{m}^{3}$ (Sommer and 129 Rasmussen, 2011). 
The city of Cordoba is placed in the south of Iberian Peninsula $\left(37^{\circ} 50^{\prime} \mathrm{N}, 4^{\circ} 45^{\prime} \mathrm{W}\right), 123 \mathrm{~m}$ a.s.l. The area has a Mediterranean climate with some continental features. The annual mean temperature is 17.8 ${ }^{\circ} \mathrm{C}$ and the annual average precipitation is $621 \mathrm{~mm}$, with hot dry summers. The nearby area is urban with agricultural surroundings (pasture and crops under rotation), olive plantations as well as shrub and/or herbaceous vegetation. Biogeographically Cordoba is located in the southern parts of the Mediterranean region. Weather data, including hourly measurements of temperature, precipitation, wind speed and direction, were provided by the central service for research support of the University of Cordoba (SCAI), based on readings taken at Rabanales Campus, located around $10 \mathrm{~km}$ north-east of the pollen sampler site.

The trap in Cordoba city is located on the roof of the Educational Sciences Faculty, at $15 \mathrm{~m}$ above ground level. The typical grass pollen season starts in April and ends in July. The peak concentration is recorded during May. Annual pollen integral varies from 1000 to 10000 pollen grains * day/m³ and daily peak concentrations vary from less than 100 to more than 800 pollen grains $/ \mathrm{m}^{3}$. Pollen concentrations were obtained using a standard protocol published by the Spanish Aerobiology Network (REA) (Galán et al., 2007). Cordoba has a special location with a valley-mountain breeze known to affect pollen concentrations (Hernandez-Ceballos et al., 2013; 2014), where winds are towards the mountains in the morning and from the mountains in the evening.Both locations follow the minimal requirements of the European Aeroallergen Network (EAN) for pollen monitoring (Galán et al., 2014).

For this study, we included data from 2008 to 2011 for Cordoba and from 2001 to 2010 for Copenhagen. Days with less than 20 grass pollen grains $/ \mathrm{m}^{3}$ were excluded from the analysis in the same way as in Peel et al. (2014) due to the large uncertainty in the daily pattern at very low concentrations. Days with rain were also excluded due to the efficiency of precipitation on removal of pollen from the atmosphere (McDonald, 1962), and the resulting effect on the profile.

Pollen data from Cordoba is counted for every hour. To reduce statistical error, as the orifice of the sampler is $2 \mathrm{~mm}$ wide and the drum runs by $2 \mathrm{~mm}$ per hour, we have re-calculated data into twohours concentrations. Time stamps have been corrected corresponding to official Danish and Spanish time (UTC+ 1 hour during autumn and winter and UTC +2 hours during spring and summer). 
magnitude. The formula for standardizing two-hours grass pollen concentrations is presented in (1), where $Z_{i}$ is the standardized two-hours value, $\mathrm{xi}$ is the real two-hours value, $\bar{X}$ is the daily mean of the two-hours pollen concentrations and SD is the daily standard deviation of the two-hours pollen concentration (Oteros et al., 2013).

$$
Z_{i}=\frac{x_{i}-\bar{X}}{S D}
$$

"Clustering" is the generic name of a big variety of procedures used for grouping a set of objects into relatively homogeneous groups. The standardized two-hours values are analysed using hierarchical cluster analysis (HCA). Hierarchical clustering analysis was performed using Ward's method, in which the distance of each element, in our case between each day, to the centroid of the cluster to which it belongs was evaluated. The mean vector of all standardized two-hours pollen concentrations was calculated, 171 determining the multivariate centroid for each cluster. The squared Euclidean distances between each 172 element and the centroid (mean vector) of all clusters were then calculated and expressed as a distances matrix. The Euclidean distance (ED) is defined as the sum of the differences between the values of the attributes of each compared pair of entities:

$$
E D=\sqrt{\sum_{i=1}^{n}\left(p_{i}-q_{i}\right)^{2}}
$$

Where $p$ and $q$ are the values of the pollen concentration at the same hour (i) of different days in 178 the study.

Finally, distances for all elements are combined. This method starts defining $n$ number of clusters, 180 where $n=$ number of study cases. The algorithm tries to minimize the total within-cluster variance after 181 merging clusters. The algorithm proceeds iteratively and at each stage joins the two most similar clusters, 182 continuing until there is just a single cluster. For every step of the iteration an optimal pair of clusters to merge needs to be found. For disjoint clusters $(X, Y, Z)$, the implementation of the Ward's minimum variance method is mathematically expressed as: 


$$
D(X \cup Y, Z)=\frac{n_{x}+n_{z}}{n_{x}+n_{y}+n_{z}} D(X, Z)+\frac{n_{y}+n_{z}}{n_{x}+n_{y}+n_{z}} D(Y, Z)-\frac{n_{z}}{n_{x}+n_{y}+n_{z}} D(X, Y)
$$

186

where $\mathrm{nx}, \mathrm{ny}$ and $\mathrm{nz}$ are the size of the clusters.

The number of natural daily pollen patterns in every city was examined graphically by a dendogram and the Elbow plot (Appendix 1). The Elbow method calculates the total intra-cluster variance according to the number of clusters.

After determined $k$, the optimal number of clusters. "K-means" conglomerate method was applied for generating clusters. Patterns in grass pollen were generated on the basis of similar two-hours standardized pollen data. From various types of cluster analysis available, this is deemed to the most appropriate, in that it provides a more flexible approach and does not assume any specific distribution of variables. Appendix 1 shows the result of k-means analysis by a "clustplot or Bivariate Cluster Plot", which is a representation of the cases and the k clusters in a 2D space ordered according to the two principal components of the data. The clustplot was with the R package "cluster" (Maechler et al., 2017).

The relationship between pollen profiles and daily weather parameters was carried out using an average-comparison method. Tested daily weather parameters were: temperature, humidity, global radiation, wind speed and wind direction. Wind direction was available for Cordoba as the hourly percentage of wind source from each octant and for Copenhagen as the predominant wind direction within 30 minutes. In the case of Cordoba, we selected the most common wind direction every hour as the prevalent direction with the aim of getting degrees' units. We calculated one value of predominant wind direction per day in degrees (0-360) by the circular average of the wind directions.

Aerobiological data are often non-normally distributed, which was verified using the Saphiro-Wilk test. Variances and homogeneity was tested by Fligner-Killeen Test (Conover et al., 1981). Due to the nonnormality and the presence of outliers (tested by plotting boxplots), a Robust Anova analysis is applied for analysing the correlation between patterns in pollen concentrations and weather parameters. Significant differences in weather variables between clusters were examined applying posthoc Tukey test to analyse in which clusters they are present. The analysis is performed using "WRS2" package of R (Mair et al., 2015; R Core Team, 2015). 
213 al., 2015, Borycka and Kasprzyk, 2014, Maya-Manzano et al., 2017). The circular average of the prevalent

214 wind direction was calculated for the days associated with each cluster. Circular statistics is performed by

215 using "Circular" package of R (Agostinelli and Lund, 2013; R Core Team, 2015). Differences in wind 216 direction between clusters were analysed by applying circular ANOVA. 


\section{Results}

A total of 259 days of data for Copenhagen and 184 days for Cordoba met the above listed criteria of no rain and pollen concentrations above 20 pollen grains $/ \mathrm{m}^{3}$. Three well defined diurnal profiles were

221 observed in both locations by the above described method. Days with high distance to cluster center were 222 not included in further analysis, since those days do not have a well-defined hourly pattern. For 223 Copenhagen, this condition applied to 69 days, and for Cordoba, 60 days. Appendix 1 shows the 224 distribution of all the cases clustered by their dissimilarities in the HC dendrogram $(A, B)$ and the Elbow 225 plot $(C, D)$, the graphical evaluation in both cases suggest that the dataset can be clustered in three well 226 defined groups $(\mathrm{K}=3)$ for each city. Appendix $1(\mathrm{E}, \mathrm{F})$ shows the distribution of the cases in a two-

227 dimensional space conformed by the component 1 and component 2 of the k-means analysis, the cases are separated in three groups according to the diurnal pollen profiles.

Figure 2 represents the average and the 95\% confidence intervals $(\mathrm{Cl})$ of each of the three predefined clusters for Cordoba. Great variation is seen between clusters in the time of peak pollen concentrations. Cluster 1 is the most frequent pattern, with $40 \%$ of the cases, showing the typical afternoon peak. Cluster 2 represents $33 \%$ of the days included, and shows an early morning peak, with substantial concentrations before daylight starts (around 7 in Cordoba). Cluster 3 represents $27 \%$ of the days included and has a two-peak pattern with morning and evening peaks. Clusters 2 and 3 are closer between then than to cluster 1 , both groups of days shows a peak in the morning, buth with the difference 237 of pollen concentrations during the night.

>>Figure 2

Figure 3 shows the average and the $95 \%-\mathrm{Cl}$ of the three pre-defined clusters for Copenhagen.

242 Cluster 1 is the most frequent pattern, with $57 \%$ of cases, showing peaks recorded during the early evening. Cluster 2 represents $13 \%$ of cases, and consists of days with peak concentrations during the night. Cluster 3 represents $30 \%$ of cases, and shows a midday-afternoon double peak. 
By applying comparison of mean methods, we found relationships between pollen patterns and

249 meteorological variables (Table 1). A total of 166 days for Copenhagen and 86 days for Cordoba were 250 included. Differences were seen between the days of the year in which most of the cases of each patterns 251 are observed in Cordoba, however not significant. Cluster 1 has the highest fraction of observations from 252 early in the season, while Cluster 3 has the main fraction of observations during the late pollen season 253 (Appendix 2). This fact could be related to the association of the flowering features of different species to 254 different patterns, but also could be a masking factor for the differences caused by meteorology. Global 255 radiation is significantly lower in cluster 1 , this is probably the consequence of cluster 1 happening more 256 frequently during the earlier part of the season.

$257 \quad$ > Table 1

258

By comparing pollen patterns with weather parameters in Copenhagen we only found a significant

260 difference for wind directions. The main wind direction was from West in Cluster 1 and from South-West 261 in Clusters 2 and 3. 


\section{Discussion}

265

266

267

268

269

270

271

272

273

274

275

276

277

278

279

280

281

282

It is known that the pollen load varies across the duration of a day, and that methods for predicting the time of the day where maximum peaks are reached have still not been developed (Bogawski and Smith, 2016). Due to pollen grains being biological particles with an important impact on human health, the study of diurnal profiles of pollen is very useful to prevent high exposures (e.g. Sommer et al., 2009). For this reason, several papers have focused on hourly pollen information and the parameters mainly influencing this variation, finding great diversity in the daily rhythms of pollination (Beddows, 1931; Jones, 1952; Kasprzyk, 2006; Muñoz Rodríguez et al., 2010; Peel et al., 2014; Pérez-Badía et al., 2011; Puc, 2012; Rojo et al., 2015).

The variation in diurnal pollen patterns is especially clear in the case of multi-species pollen types such as Poaceae, and the time of maximum concentration is difficult to predict as an average that only shows one most frequently found pattern without accounting for other possible patterns. Alba et al. (2000) found also that there is not a single diurnal pattern even for pollen measurements originating from a single species (Olea europaea L.). They postulated that limiting the visualizing of the average behaviour of airborne pollen (through the average diurnal pattern) limits the analysis of the diurnal pollen pattern, resulting in the understanding to be incomplete. They found that $54 \%$ of the observed days fitted a single dispersal pattern, on the remaining days (46\%) the pollen dispersal was highly irregular. In our study we found three possible patterns where approximately $70 \%$ of the studied days without rain and a daily pollen concentration above 20 pollen grains $\mathrm{m}-3$ could be fitted. For $27 \%$ of days for Copenhagen, and $32 \%$ of days for Cordoba the pattern showed a high distance to cluster center, i.e. a pattern not fitting any of the three clusters.

Many factors are involved in the variation of the diurnal pattern of pollen concentrations. In the case of Poaceae, differences in pollination features of the different species can have an important influence. Several papers report considerable variation in the pattern, linking this to species flowering at different time, peak occurring mostly in the morning or in the afternoon (Kapyla, 1981; Peel et al., 2014). It could therefore be important to determine this by a dedicated phenological study focusing on the species that contribute to the majority of airborne grass pollen concentrations in order to determine the time of the day at which they liberate the pollen, and potential differences in the effect of meteorology on the different species. This can also be expected to be site-specific, and transferable uniform patterns may not be possible, however uniform methods may be developed. 
León Ruiz et al. (2011) found that in Cordoba only four species were major contributors to the Poaceae 295 airborne pollen curve (Dactylis glomerata, Lolium rigidum, Trisetaria panacea, Vulpia geniculata) while Kraaijeveld et al (2015) found a larger number of important species in the Netherlands. Cebrino et al.

297 (2016) support these results and show that the majority of the pollen sources are found locally. Peel et al.

298 (2014) found a relationship between diurnal profiles and the time of season potentially linking this to the 299 flowering of different species. This fact could be explained by the existence of different pollination 300 features depending on the grass species. In this study we did not see a clear difference related to time of 301 season, and could therefore not explain the patterns as being primarily driven by the succession of 302 flowering species.

Another factor that must be taken into account is the distance between pollen sources and the trap (Perez Badia et al., 2011), although this fact could be less relevant for Poaceae as these taxa are densely distributed everywhere, inside and around cities. Nevertheless, distance from the pollen source can be also of great importance and show large variations within short distances (Skjøth et al., 2013b). Depending on the distance from the pollen source and flowering phenology, wind direction seems to be determinant for explaining some intra-diurnal variations of pollen loads (Rojo et al., 2015). In our study the wind direction showed significant differences between clusters for Copenhagen, with Cluster 1 having more winds from West and Southwest. This is the most frequent pattern with early evening peaks. A large residential area with gardens, lawns and associated grass covered recreational areas is located approximately $0.5-1.5 \mathrm{~km}$ in this direction. However, whether this area is a major source of the pollen will highly depend on the cutting frequency of the lawns and meadows (Skjøth et al., 2013b). seen here. Differences are therefore unlikely due to differences in source areas for this site, however a separate analysis would be required to establish this. Our result along with the previous results by Norris-

319 Hill and Emberlin (1991) suggest that the foot print area could be an important factor to take into account 320 in further grass pollen studies. Even highly local sources could be of great importance (Skjøth et al 2013). 321 Ideally they should focus on both the variation in the daily pattern as in our study as well as the dominating 322 species and the associated ecosystems found within the atmospheric foot print.

323 Different grass species are associated with main ecosystems and geographical regions as defined by the biogeographical regions of Europe and used in the habitats directive. This is clearly illustrated in the 
contribution from a large number of species to the overall grass pollen integral found in Leiden, within the Atlantic biogeographical region (Kraaijeveld et al., 2015) and four the dominating species found in Cordoba (Cebrino et al., 2016). In the Poaceae family, the liberation of pollen is controlled by factors inherent to each species and occurs in a short period of hours each day but pollen grains can remain in the air where their dispersion is again affected by meteorological parameters (Myszkowska, 2014). These meteorological effects also vary during the day, e.g. as in the valley winds affecting Cordoba and the associated pollen concentrations (Hernandez-Ceballos et al., 2013; 2014). In this sense, Norris-Hill and Emberlin (1991) tried to divide days into categories taking into account temperature, humidity and wind direction, finding small differences in the time of maximum pollen concentration with temperature and wind direction.

This study was carried out in two different urban environments. Exposure to grass pollen in urban environments is particular important because some air pollutants seems to correlate with the daily patterns of pollen concentrations ( $\varnothing$ rby et al., 2015). Puc (2012) also saw strong correlation between intra-hourly pollen concentrations and gaseous air pollutants. This is important because co-exposure of air pollutants and pollen can reduce the threshold for an allergenic response (Molfino et al., 1991; D'Amato et al., 2010). In the case of Cordoba (Spain) a previous study showed that the peaks of nonbiological particles in the air throughout the day are related to activities carried out by human beings in the city occurring in the morning and late in the evenings (commercial and working hours), which are probably related with resuspension process of particles (Cariñanos et al., 1999). Many of these particles originating from traffic pollution. During these hours sensitive individuals must exercise precautions. Simoleit et al. (2015) also comment that the combination between pollution and pollen load in the air represent a special health threat for urban population as pollen are considered to be more allergenic in a polluted atmosphere (D'Amato et al, 2010; Schiavoni et al 2017). Combined with the current study indicating that a high proportion of days where pollen peaks at these times, susceptible induvial may be of increased risk and must exercise precautions. The combined effects of air pollutants and aeroallergens is an important area, in particular in the urban zone, and that there need to be a focus on short-term exposure of both air pollutants and aeroallergens.

Although the two sites can be assumed to have differences in the composition of species, both sites had three clusters with some similarity in the daily pattern: Cluster type 1: late afternoon peaks, 354 Cluster type 2: partly or entirely dominated by night time/early morning conditions, and Cluster type 3: a double peak. This result is partly the consequence of the method, determining the most distinctively 
356 different patterns. However, even with great differences in species composition, meteorology and 357 dominating local wind patterns and patterns objectively analysed through statistical clustering, both sites 358 showed a uniform peak in the afternoon or evening as the most frequent pattern. For Denmark, the 359 evening peak was also seen as the dominating peak in the main season in the city of Aarhus (Peel et al, 360 2014). This indicates that the advice given for allergen-avoidance should emphasize that peak 361 concentrations may occur at all times of day, but the most frequent peak, dominating the seasonal peak, 362 is in the early evening.

363 
Here we propose a new method based on clustering methodology and standardization of pollen concentrations to study variations of airborne pollen in two-hours periods. The different hourly-patterns 367 recorded at southern Europe (Spain) and northern Europe (Denmark) could not directly be related with 368 the meteorological conditions at either location.

The studies carried out in both cities show strong variation in the diurnal pattern of grass pollen 370 in the air, with approximately $70 \%$ of days (without rain and daily pollen concentrations above 20 pollen 371 grains $\mathrm{m}-3$ ) fitting 3 statistically (although not significant) determined clusters of patterns, with peaks at 372 either both morning, midday, evening or night. For both sites however, one late afternoon (Cordoba) or 373 early evening peak (Copenhagen) is the most frequent distinctive pattern.

374 The peak can occur at all hours of the day, most likely depending on flowering patterns of the 375 dominant grass species and a complex effect of meteorological parameters. In view of the results average 376 curves are not satisfactory for describing the diurnal pattern of grass pollen as they mask the day to day 377 variation and long term season effects. 


\section{Acknowledgments}

380

This study was partly supported by Ministerio de Economía y Competitividad I+D+I "RETOS

381 INVESTIGACIÓN" under project "Study on phenological trends in plants of Western Mediterranean and its

382 relation to climate change (FENOMED)". The Danish Asthma Allergy Association is acknowledged for

383 providing the pollen monitoring data from the national monitoring station in Copenhagen. We also

384 acknowledge financial support from the European Commission for the SUPREME project, with ID:

385 CIG631745 (to CAS). We acknowledge Helmholtz Zentrum München for the Postdoctoral Fellowship

386 Program III 2017-2019.

387 


\section{References}

Agostinelli C. and Lund U. 2013. R package 'circular': Circular Statistics (version 0.4-7). URL https://rforge.r-project.org/projects/circular/

Alba F., Díaz de la Guardia C. and Comtois P. 2000. The effect of meteorological parameters on diurnal patterns of airborne olive pollen concentration. Grana 39: 200-208

Alcázar P., Galán C., Cariñanos C. and Domínguez-Vilches E. 1999. Diurnal variation of airborne pollen at two different heights. Invest Allergol Clin Immunol. 9(2): 89-95

Beddows A. R. 1931. Seed-setting and flowering in various grasses. Rep. No. Series H No. 12, Welsh Plant Breeding Station Bulletin.

Bogawski P. and Smith M. 2016. Pollen nightmare: elevated airborne pollen levels at night. Aerobiologia 1-4.

Borycka K. and Kasprzyk I. 2014. Evaluation of the effect of weather on concentrations of airborne Artemisia pollen using circular statistic. Acta Agrobotanica, 67(1).

Burbach G.J., Heinzerling L.M., Edenharter G, Bachert C., Bindslev-Jensen C., Bonini S., Bousquet J., 403 
D’Amato G., Cecchi L., D’Amato M. and Liccardi G. 2010. Urban air pollution and climate change as environmental risk factors of respiratory allergy: an update. J Investig Allergol Clin Immunol 20(2): 95-102.

Galán C., Cariñanos P., Alcázar P. and Domínguez-Vilches E. 2007. Spanish Aerobiology Network, Management and Quality Manual. Servicio de Publicaciones de la Universidad de Cordoba.

Galán C., Cuevas J., Infante F. and Domínguez E. 1989. Seasonal and diurnal variation of pollen from Gramineae in the atmosphere of Cordoba, Spain. Allergologia et Immunopathologia 17(5): 245249.

Galán C., Smith M., Thibaudon M., Frenguelli G., Oteros J., Gehrig R., Berger, U., Clot, B. and Brandao, R. 2014. Pollen monitoring: minimum requirements and reproducibility of analysis. Aerobiologia 30: 385-395

Galán C., Ariatti A., Bonini M., Clot B., Crouzy B., Dahl A., Levetin E., Li D. W., Mandrioli P., Rogers C.A., Thibaudon M., Sauliene I., Skjoth C., Smith M. and Sofiev M. 2017. Recommended terminology for aerobiological studies. Aerobiologia, 33(3), 293-295.

García-Mozo H., Galán C., Alcázar P., Díaz de la Guardia C., Nieto-Lugilde D., Recio M., Hidalgo P., GónzalezMinero F., Ruiz L. and Domínguez-Vilches E. 2010. Trends in grass pollen season in southern Spain. Aerobiologia 26: 157-169.

Goldberg C., Buch H., Moseholm L. and Weeke E.R. 1988. Airborne pollen records in Denmark, 1977-1986. Grana 27: 209-217

Hernández-Ceballos M.A., Adame J.A., Bolívar J.P. and De la Morena B.A. 2013 A mesoscale simulation of coastal circulation in the Guadalquivir valley (southwestern Iberian Peninsula) using the WRFARW model. Atmos Res 124:1-20

Hernández-Ceballos M.A, Skjøth C.A., García-Mozo H., Bolívar J.P., Galán C. 2014. Improvement in the accuracy of backtrajectories using WRF to identify pollen sources in southern Iberian Peninsula: International journal of biometeorology 58 (10): 2031-204

Hirst J.M. 1952. An automatic volumetric spore-trap. Ann Appl Biol 39: 257-265

Hirst, J. M. 1953. Changes in atmospheric spore content: diurnal periodicity and the effects of weather. Transactions of the British Mycological Society 36(4): 375-393. 
Hyde H. A. and D. A. Williams. 1945. Studies in atmospheric pollen, New Phytologist 44(1): 83-94.

Jones M. D. 1952. Time of day of pollen shedding of some hay fever plants. Journal of Allergy and Clinical Immunology 23(3): 247-258.

Käpyla M. 1981. Diurnal variation of non-arboreal pollen in the air in Finland. Grana 20: 55-59

Kasprzyk I. 2006. Comparative study of seasonal and intradiurnal variation of airborne herbaceous pollen in urban and rural areas. Aerobiologia 22: 185-195

Kraaijeveld K., Weger L. A., Ventayol Garcia M., Buermans H., Frank J., Hiemstra P.S. and Dunnen J. T. 2015. Efficient and sensitive identification and quantification of airborne pollen using nextgeneration DNA sequencing. Molecular ecology resources 15:8-16.

León-Ruiz E., Alcázar P., Domínguez-Vilches E. and Galán C. 2011. Study of Poaceae phenology in a Mediterranean climate. Which species contribute most to airborne pollen counts? Aerobiologia 27: 37-50.

Maechler M., Rousseeuw P., Struyf A., Hubert M., Hornik K. 2017. cluster: Cluster Analysis Basics and Extensions. R package version 2.0.6.

Mair P., Schoenbrodt F. and Wilcox R. 2015. WRS2: Wilcox robust estimation and testing. R package.

Maya-Manzano J. M., Sadyś M., Tormo-Molina R., Fernández-Rodríguez S., Oteros J., Silva-Palacios I. and Gonzalo-Garijo A. 2017. Relationships between airborne pollen grains, wind direction and land cover using GIS and circular statistics. Science of the Total Environment. In press (DOI: http://dx.doi.org/10.1016/j.scitotenv.2017.01.085)

McDonald J.E. 1962. Collection and washout of airborne pollens and spores by raindrops. Science 135: 435-437.

Molfino N.A., Wright S.C., Katz I., Tarlo S., Silverman F., McClean P.A., Slutsky A.S., Zamel N., Szalai J.P. and Raizenne M. 1991. Effect of low concentrations of ozone on inhaled allergen responses in asthmatic subjects. The Lancet 338: 199-203.

Myszkowska, D. 2014. Poaceae pollen in the air depending on the thermal conditions. International Journal of Biometeorology 58(5): 975-986. 
Muñoz Rodríguez AF., Silva Palacios I. and Tormo Molina R. 2010. Influence of meteorological parameters in hourly patterns of grass (Poaceace) pollen concentration 17: 87-100

Norris-Hill J. and Emberlin J. 1991. Diurnal variation of pollen concentration in the air of north-central London. Grana 30: 229-234

Ørby P. V., Peel R. G., Skjøth C. A., Schlünssen V., Bønløkke J. H., Ellermann T., Brændholt A., Sigsgaard T. and Hertel O. 2015. An assessment of the potential for co-exposure to allergenic pollen and air pollution in Copenhagen, Denmark, Urban Climate 14: 457-474.

Oteros J., Galán C., Alcázar P. and Domínguez-Vilches E. 2013. Quality control in bio-monitoring networks, Spanish Aerobiology Network. Science of the Total Environment 443: 559-565.

Pérez-Badia R., Rapp A., Vaquero C. and Fernández-González F. 2011. Aerobiological study in east-central Iberian Peninsula: pollen diversity and dynamics for major taxa. Annals of Agricultural and Environmental Medicine 18: 99-111

Peel R.G., Ørby P.V., Skjøth C.A., .Kennedy R., Schlünssen V., Smith M., Sommer J. and Hertel O. 2014. Seasonal variation in diurnal atmospheric grass pollen concentration profiles. Biogeosciences 11: 821-832.

Puc M. 2012. Influence of meteorological parameters and air pollution on hourly fluctuation of birch (Betula L.) and ash (Fraxinus L.) airborne pollen. Annals of Agricultural and Environmental Medicine 19 (4): 660-665

R Core Team 2015. R: A language and environment for statistical computing. R Foundation for Statistical Computing, Vienna, Austria. URL http://www.R-project.org/

Rojo J., Rapp A., Lara B., Fernández-González F. and Pérez-Badia R. 2015. Effect of land uses and wind direction on the contribution of local sources to airborne pollen. Science of the Total Environment 538: 672-682.

Sadyś M., Kennedy R. and Skjøth C. A. 2015. An analysis of local wind and air mass directions and their impact on Cladosporium distribution using HYSPLIT and circular statistics. Fungal Ecology 18: 5666.

Schiavoni, G., D’Amato, G. and Afferni, C. 2017. The dangerous liaison between pollens and airpollution in respiratory allergy. Ann. Allergy Asthma Immunol 118: 269-275. 
497 Simoleit A., Gauger U., Mücke HG., Werchan M., Obstová B., Zuberbier T. and Bergmann KC. 2015. 498 Intradiurnal patterns of allergenic airborne pollen near a city motorway in Berlin, Germany. 499 Aerobiologia. DOI 10.1007/s10453-015-9390-6

500 SkjøthC.A., Jäger S., Šikoparija B. and EAN-Network. 2013. Pollen sources. p. 9-28. Allergenic pollen: a 501 review of the production, release, distribution and health impacts. Springer.

502 Skjøth C. A., Ørby P. V., Becker T., Geels C., Schlünssen V., Sigsgaard T. and Hertel, O. 2013. Identifying 503 urban sources as cause of elevated grass pollen concentrations using GIS and remote sensing. $504 \quad$ Biogeosciences 10(1): 541-554.

505 Smith M., Jager S., Berger U., Sikoparija B., Hallsdottir M., Sauliene I., Bergmann K., Pashley C.H., Weger 506 L. and Majkowska-Wojciechowska B. 2014. Geographic and temporal variations in pollen $507 \quad$ exposure across Europe. Allergy 69: 913-923.

508 Sommer J. and Rasmussen A. 2011. Pollen- \& Sporemålinger i Danmark. Sæsonnen 2011. / Pollen and 509 spore measurements in Denmark. Season 2011. Astma Allergi Danmark.

510 Sommer J., Plaschke P. and Poulsen L.K. 2009. Allergiske sygdomme--pollenallergi og klimaaendringer. 511 Ugeskrift for Læger. 


\begin{tabular}{c|c|c|c|c}
\hline & sig. & $\begin{array}{c}\mathrm{C} 1 \\
\text { Mean }(\mathrm{SD})\end{array}$ & $\begin{array}{c}\mathrm{C} 2 \\
\text { Mean }(\mathrm{SD})\end{array}$ & $\begin{array}{c}\mathrm{C} 3 \\
\text { Mean (SD) }\end{array}$ \\
\hline DOY & 0.09 & $136.82(18.58)$ & $143.86(17.69)$ & $144.91(18.39)$ \\
\hline Temperature $\left({ }^{\circ} \mathrm{C}\right)$ & 0.14 & $20.13(3.64)$ & $21.33(3.45)$ & $21.98(3.1)$ \\
\hline Humidity $(\%)$ & 0.56 & $55.94(11.43)$ & $52.99(10.22)$ & $55.23(7.52)$ \\
\hline Global radiation $\left(\mathrm{W} / \mathrm{m}^{2}\right)$ & $\mathbf{0 . 0 2}$ & $286.34(42.82)$ & $314.00(43.98)$ & $314.47(31.83)$ \\
\hline Wind speed $(\mathrm{m} / \mathrm{s})$ & 0.29 & $1.54(0.48)$ & $1.69(0.57)$ & $1.82(0.6)$ \\
\hline Wind direction $\left({ }^{\circ}\right)$ & 0.40 & $351.38\left(248^{\circ}\right.$ to $\left.54^{\circ}\right)$ & $9.30\left(256^{\circ}\right.$ to $\left.77^{\circ}\right)$ & $8.20\left(264^{\circ}\right.$ to $\left.58^{\circ}\right)$ \\
\hline
\end{tabular}

514 Table 1. Córdoba (Spain). Differences in daily environmental parameters between days defined with 515 different hourly patterns in airborne pollen. Robust ANOVA significance. C1, Cluster 1. C2, Cluster 2. 516 C3, Cluster 3. DOY; Day of the Year. Wind direction is calculated by circular statistics approach. Only 517 maximum and minimum are shown for wind direction, not SD, due to the circular properties. 


\begin{tabular}{c|c|c|c|c}
\hline & sig. & $\begin{array}{c}\mathrm{C} 1 \\
\text { Mean (SD) }\end{array}$ & $\begin{array}{c}\text { C2 } \\
\text { Mean (SD) }\end{array}$ & $\begin{array}{c}\text { C3 } \\
\text { Mean (SD) }\end{array}$ \\
\hline DOY & 0.47 & $174.06(13.15)$ & $177.6(15.37)$ & $175.74(14.61)$ \\
\hline Temperature $\left({ }^{\circ} \mathrm{C}\right)$ & 0.20 & $17.11(3.09)$ & $17.98(2.89)$ & $17.69(2.69)$ \\
\hline Humidity $(\%)$ & 0.72 & $66.78(9.74)$ & $69.64(10.18)$ & $68.05(7.94)$ \\
\hline Global radiation $\left(\mathrm{W} / \mathrm{m}^{2}\right)$ & 0.19 & $272.64(59.46)$ & $246.25(71.24)$ & $255.12(69.81)$ \\
\hline Wind speed $(\mathrm{m} / \mathrm{s})$ & 0.17 & $3.55(0.95)$ & $3.16(1)$ & $3.45(0.98)$ \\
\hline Wind direction $\left({ }^{\circ}\right)$ & $\mathbf{0 . 0 1}$ & $267.34\left(90^{\circ}\right.$ to $\left.78^{\circ}\right)$ & $211.6\left(35^{\circ}\right.$ to $\left.333^{\circ}\right)$ & $221.2\left(54^{\circ}\right.$ to $\left.45^{\circ}\right)$ \\
\hline
\end{tabular}

Table 2. Copenhagen (Denmark). Differences in daily environmental parameters between days defined with different hourly patterns in airborne pollen. Robust ANOVA significance. C1, Cluster 1. C2, Cluster

522 2. C3, Cluster 3. DOY; Day of the Year. Wind direction is calculated by circular statistics approach. Only 523 maximum and minimum are shown for wind direction, not SD, due to the circular properties. 
525 Figure 1. Biogeographical regions and the locations of Copenhagen and Cordoba.

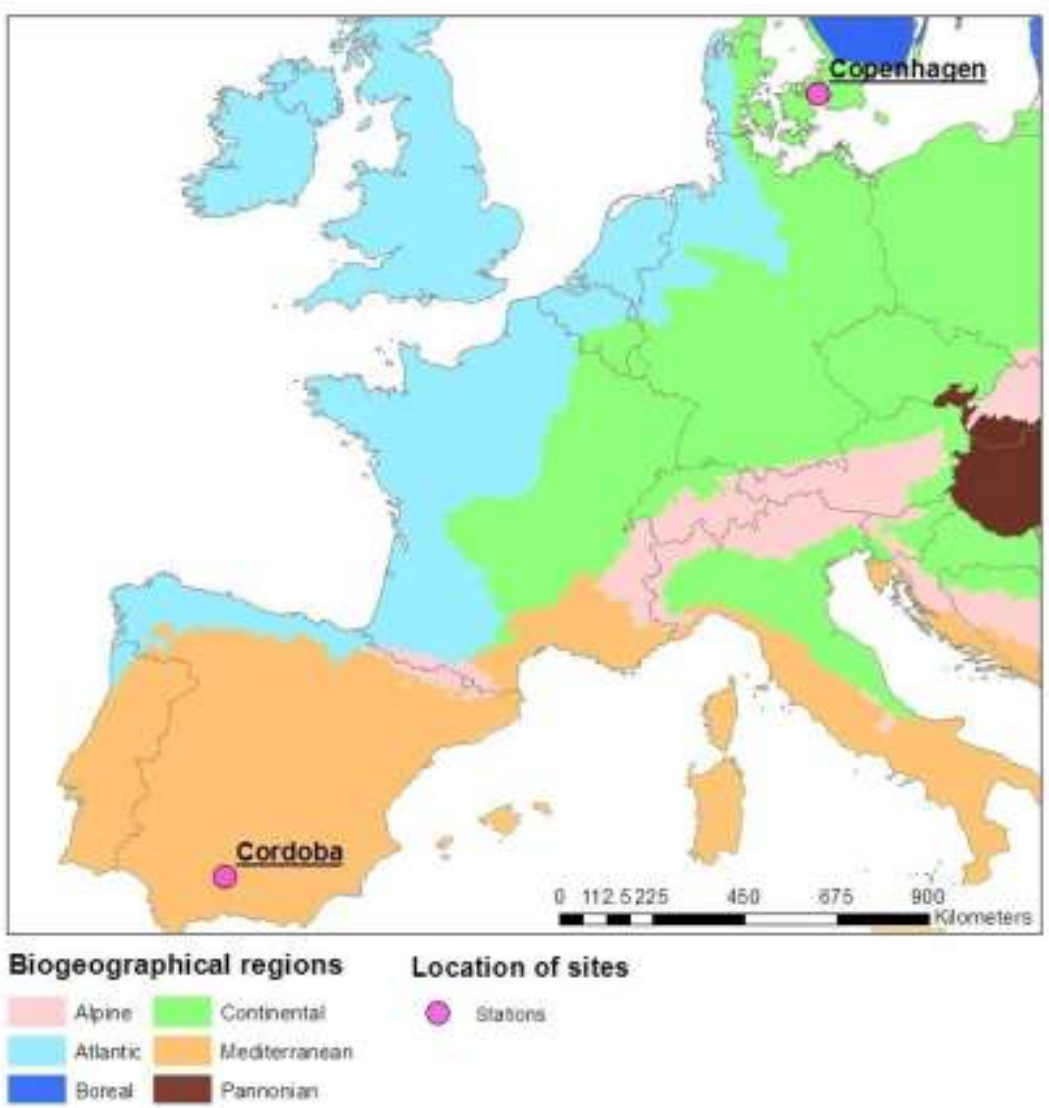

526

527 
Figure 2. Average and $95 \%$ confidence intervals (dashed lines) for each cluster of profiles of grass pollen concentrations in Córdoba, Spain. Cases: Cluster 1: 40\%, Cluster 2: 33\%, Cluster 3: 27\%.

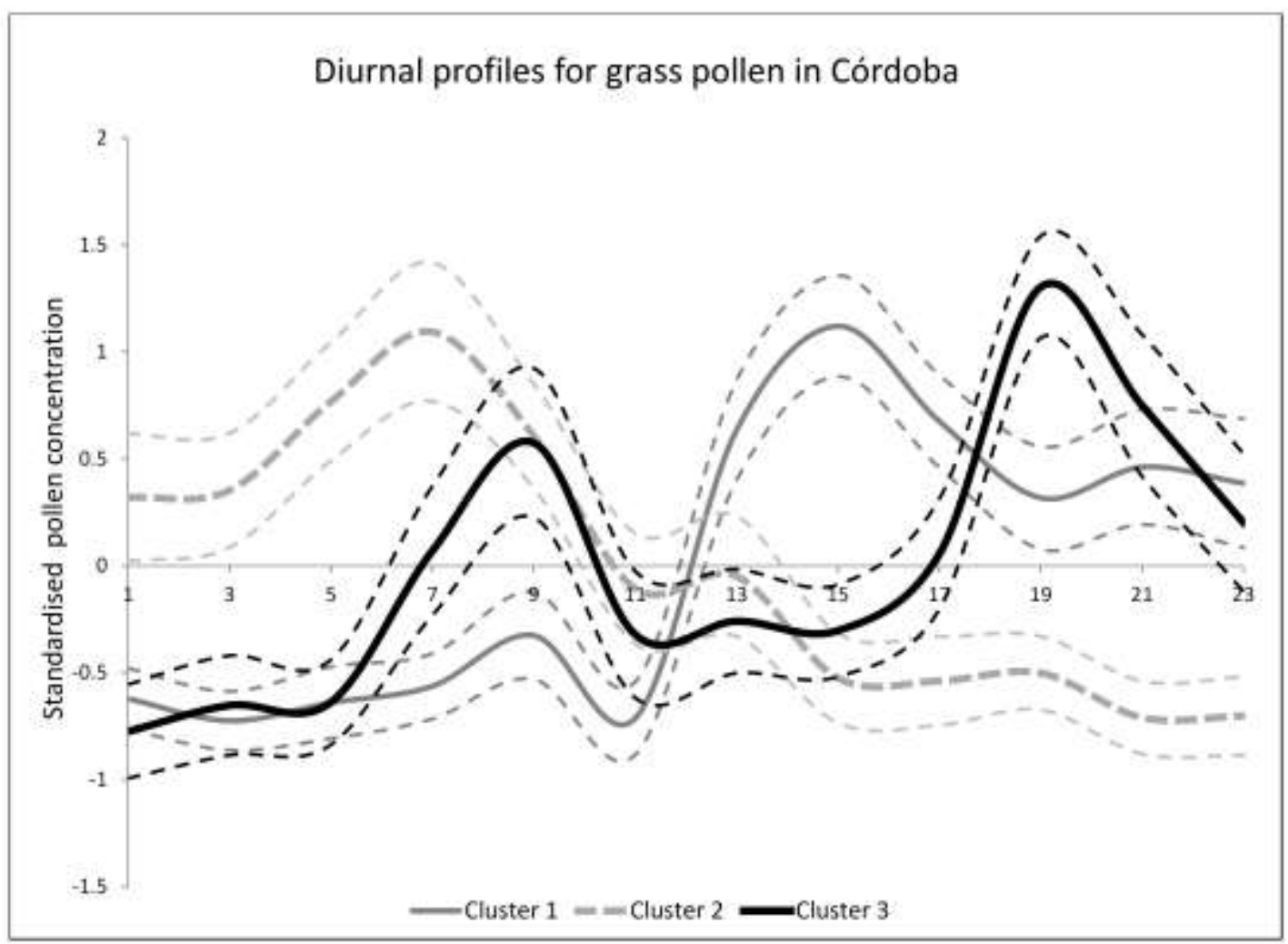


532 Figure 3. Average and 95\% confidence intervals (dashed lines) for each cluster of profiles of grass pollen 533 concentrations in Copenhagen, Denmark. Cases: Cluster 1: 57\%, Cluster 2: 13\%, Cluster 3: 30\%.

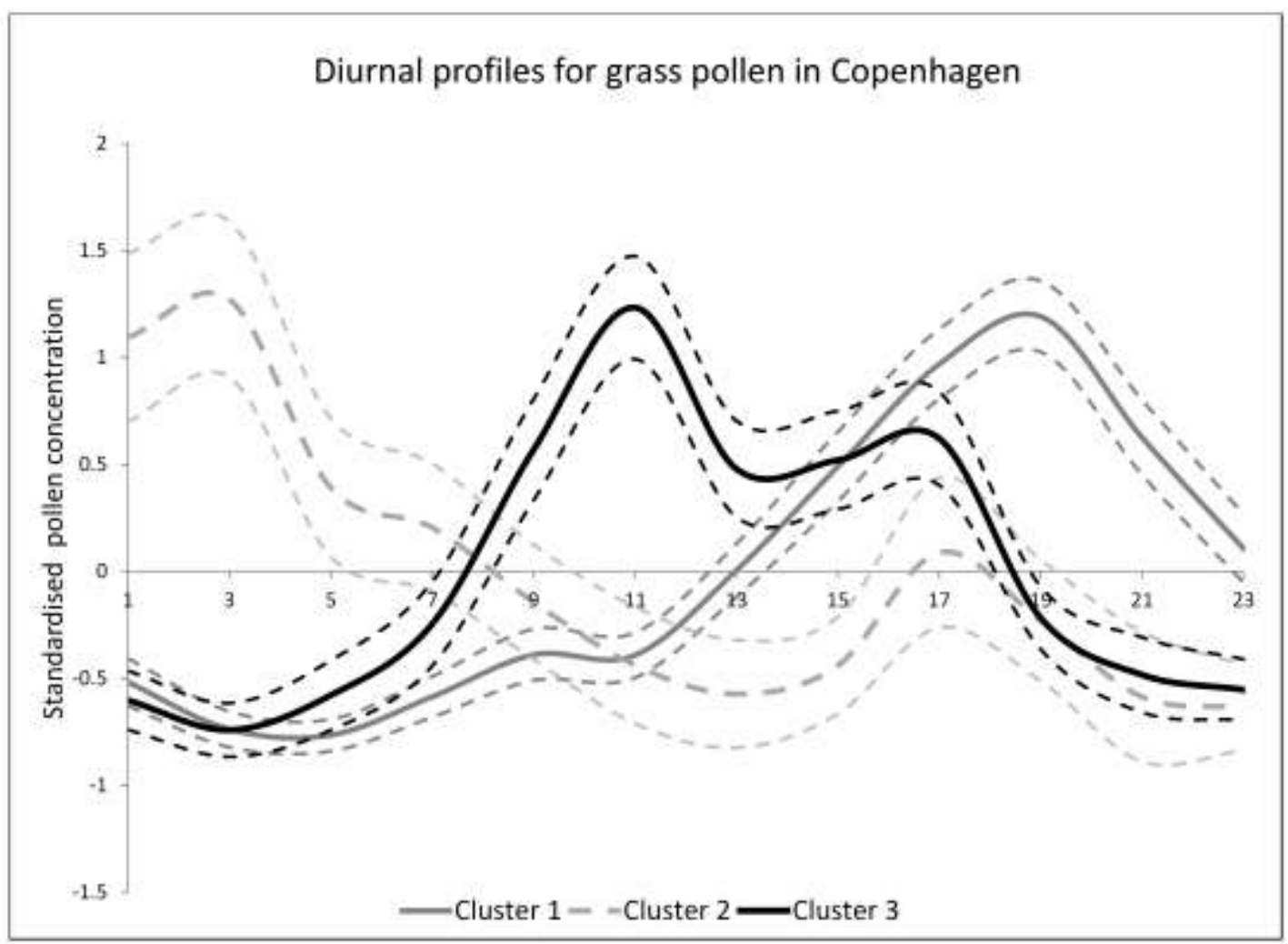


536 Appendix 1. Hierarchical Clustering Ward dendrogram of the study cases in Cordoba location (A) and 537 Copenhaguen (B). Elbow plot with the total sum of squares showing the explained variability in the study 538 cases depending on the numer of clusters (K) in Cordoba(C) and Copenhagen (D). Clusterplot of the 539 principal components ( $x$ axis: Component 1 , y axis: Component 2 ) of the k-means analysis ( $k=3$ ) in Cordoba 540 location (E) and Copenhaguen (F). 
Cordoba

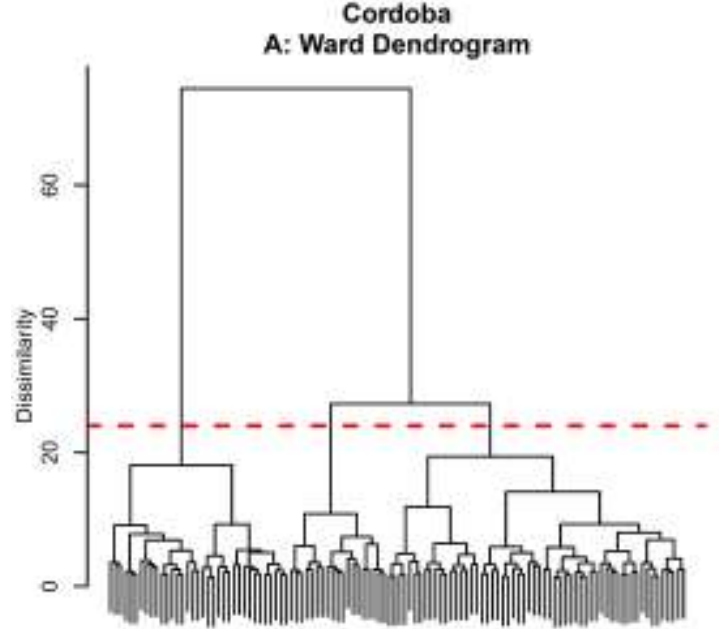

Day of the Year

C: Elbow plot
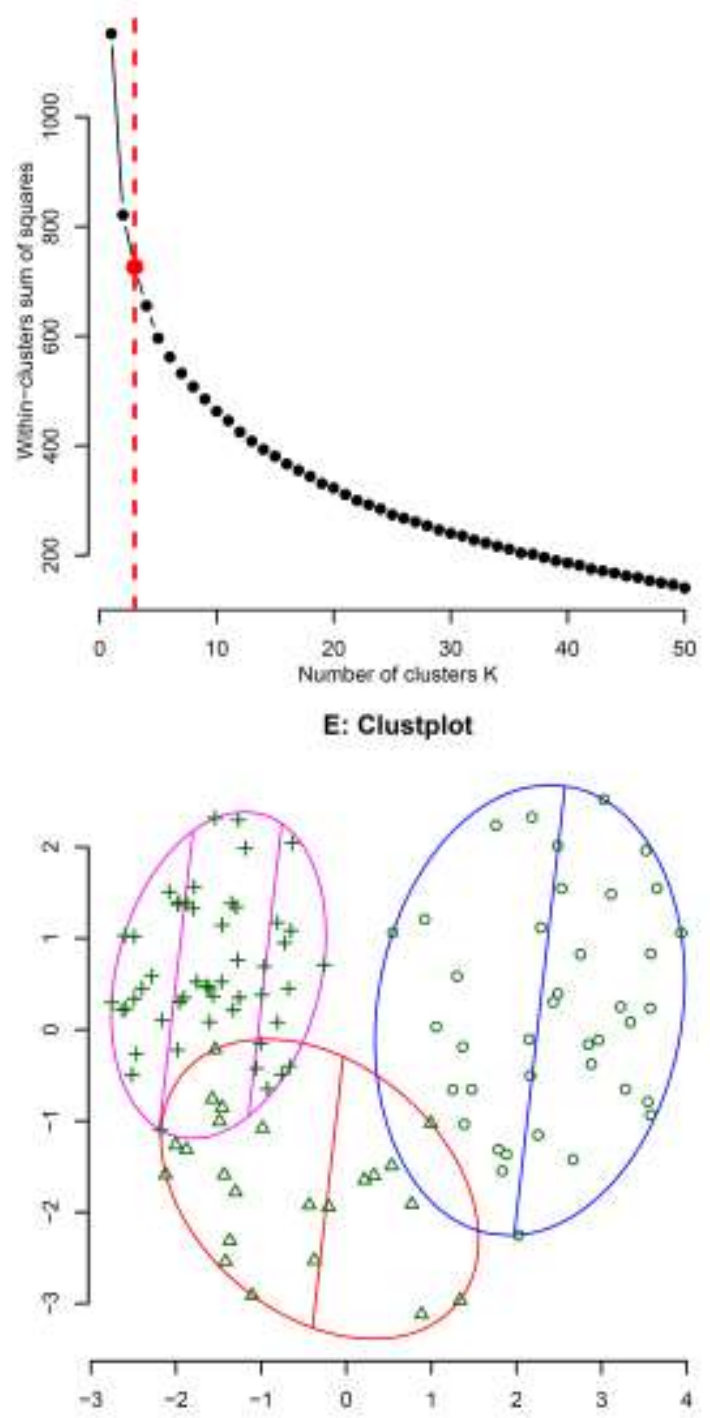

Copenhague

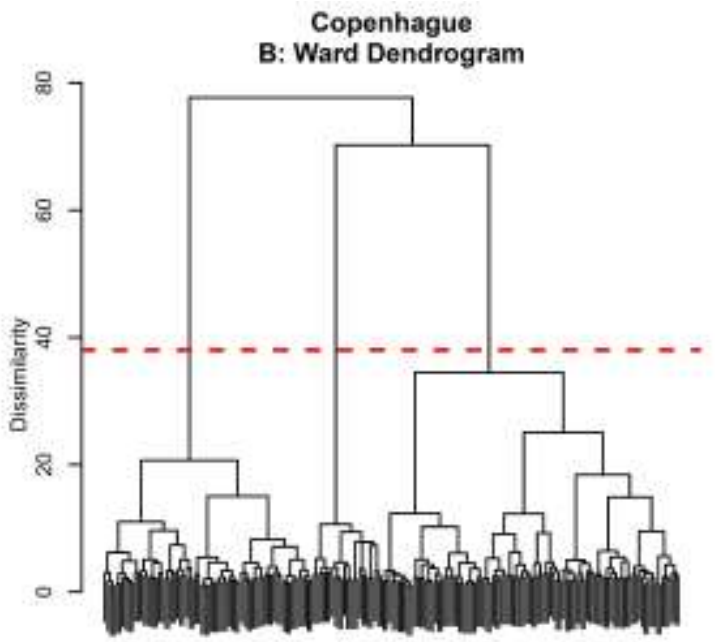

Day of the Yeat

D: Elbow plot

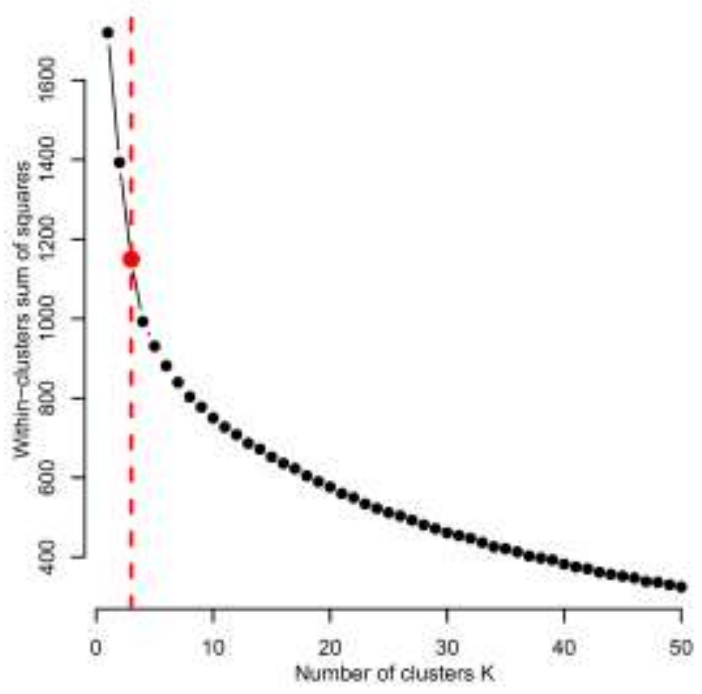

F: Clustplot

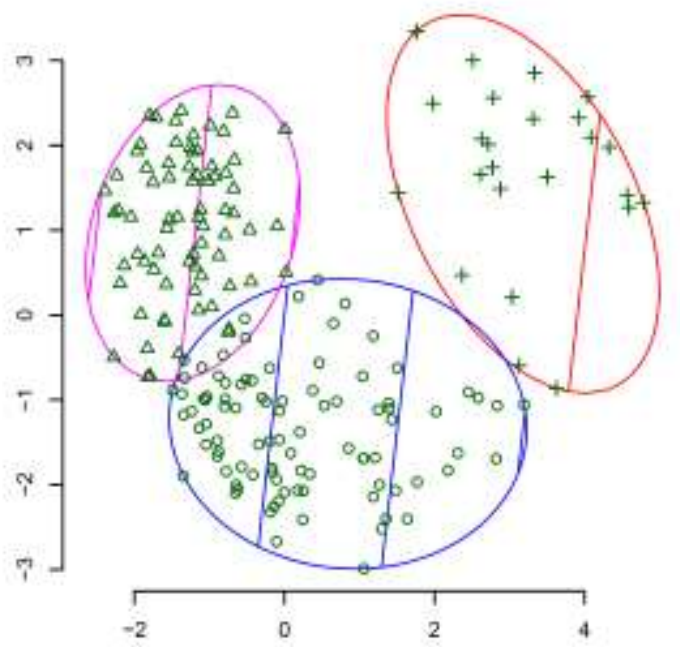


542 Appendix 2. Distribution of the days of the year in the study cases according to the cluster in Copenhagen 543 and Cordoba.

Day of year for data in each cluster.

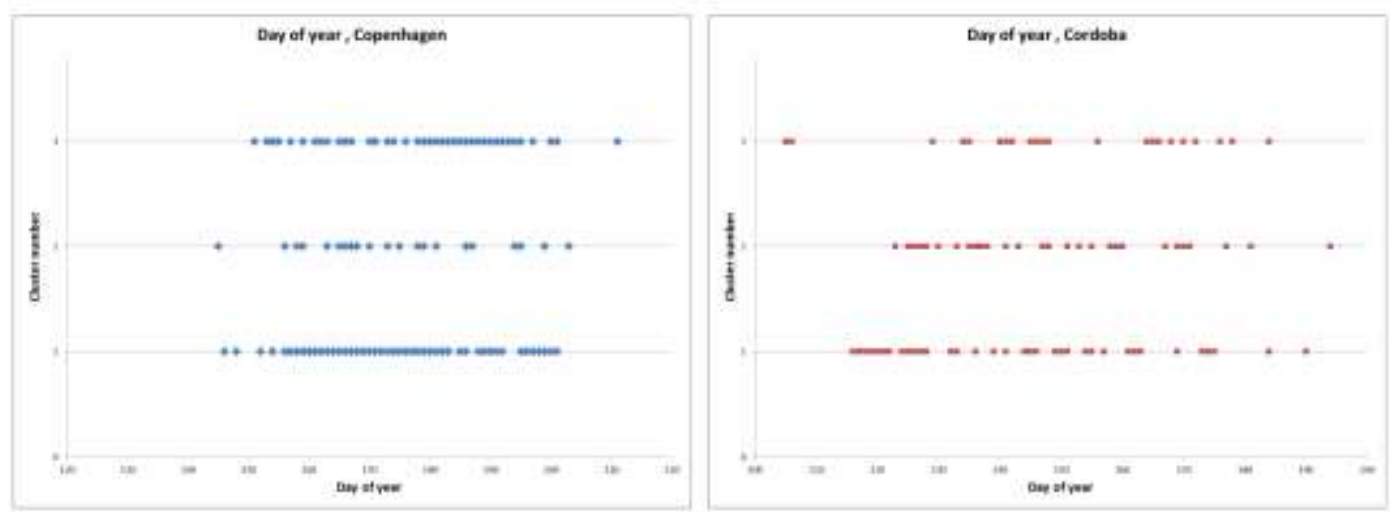

544 